\title{
Safety and Efficacy of Minimally Invasive McKeown Esophagectomy in 1023 Consecutive Esophageal Cancer Patients: A Single-Center Experience
}

\section{Xiao-Dong Zheng}

Tianjin Medical University General Hospital https://orcid.org/0000-0002-5495-3216

\section{Shi-cong Li}

Tianjin Medical University General Hospital

\section{Chao Lu}

Tianjin Medical University General Hospital

\section{Wei-Ming Zhang}

The fourth affiliate hospital of Henan University of science and technology

\section{Jian-Bin Hou}

Anyang tumor hospital the fourth affiliated hospital of Henan University of science and Technology

\section{Ke-Feng Shi}

Anyang tumor hospital the affiliated hospital of Henan university of science and technology

\section{Peng Zhang ( $\nabla$ xwkzhangpeng@163.com )}

Tianjin Medical University General Hospital

\section{Research article}

Keywords: ESOPHAGEAL CANCER, CANCER TREATMENT, MINIMALLY INVASIVE ESOPHAGECTOMY, COMPLICATION, PROGNOSIS

Posted Date: April 20th, 2021

DOI: https://doi.org/10.21203/rs.3.rs-410081/v1

License: (c) (i) This work is licensed under a Creative Commons Attribution 4.0 International License. Read Full License

Version of Record: A version of this preprint was published at Journal of Cardiothoracic Surgery on March 15th, 2022. See the published version at https://doi.org/10.1186/s13019-022-01781-2. 


\section{Abstract \\ Objective}

By analyzing the perioperative, postoperative complications and long-term overall survival time, we summarized the 8-year experience of minimally invasive McKeown esophagectomy for esophageal cancer in a single medical center.

\section{Methods}

This retrospective follow-up study included 1023 consecutive patients with esophageal cancer who underwent MIE-McKeown between Mar 2013 and Oct 2020. Relevant variables were collected and evaluated. Overall survival (OS) was analyzed by Kaplan-Meier method.

\section{Results}

For 1023 esophageal cancer undergoing MIE-McKeown, the main intraoperative complications were bleeding $(3.0 \%, 31 / 1023)$ and tracheal injury $(1.7 \%, 17 / 1023)$. There was no death occurred during operation. The conversion rate of thoracoscopy to thoracotomy was $2.2 \%(22 / 1023)$, and laparoscopy to laparotomy was $0.3 \%(3 / 1023)$. The postoperative morbidity of complications was $36.2 \%(370 / 1023)$, of which anastomotic leakage $7.7 \%$ (79/1023), pulmonary complication $13.4 \%(137 / 1023)$, chylothorax $2.3 \%(24 / 1023)$, and recurrent laryngeal nerve injury $8.8 \%$ (90/1023). The radical resection rate (R0) was $96.0 \%$ (982/1023), 30-day mortality was $0.3 \%$ (3/1023). For 1000 cases with squamous cell carcinoma, the estimated 3-year and 5-year overall survival was $65.1 \%$ and $52.7 \%$ respectively. In addition, neoadjuvant chemotherapy offered 5-year survival advantage in advanced stage patients (for stage III: $53.1 \%$ vs. $32.9 \%$, and for stage IV: $20.3 \%$ vs. $7.1 \%$ ).

\section{Conclusions}

This retrospective single center study demonstrates that MIE-McKeown procedure is feasible and safe with low perioperative and postoperative complications' morbidity, and acceptable long-term oncologic results. Meanwhile, neoadjuvant chemotherapy followed by surgery may improve long-term survival for patients with advanced esophageal squamous cell carcinoma.

\section{Introduction}

Esophageal cancer ranks the seventh common malignant tumor and the sixth leading cause of tumorrelated death worldwide in 2018. In China, it is the sixth most frequently diagnosed cancer and the fourth leading cause of cancer death[1]. Despite great advances have been made in its diagnosis, surgical treatment and neoadjuvant therapy, probably due to its aggressiveness, the overall 5-year survival rate 
rests around $30 \%[2,3]$. Esophagectomy is an important, potentially curative treatment for resectable esophageal cancer. However, the conventional open esophagectomy is a technically challenging procedure, which is associated with significant complications' morbidity and mortality. Therefore, minimally invasive esophagectomy (MIE) has been adopted worldwide with hope of lower invasiveness.

Currently, MIE is commonly performed using two approaches: the MIE-McKeown and MIE Ivor-Lewis. MIEMcKeown with three-field lymph node dissection, which may obtain better survival than the two-field lymph node dissection, has evolved as one standard procedure of resectable esophageal cancer[6, 7]. However, there is no definitive scientific evidence supporting that the use of MIE as an alternative to open esophagectomy has advantages of significantly lowering morbidity of complications and mortality $[8,9$, 10]. Moreover, the oncologic outcomes after minimally invasive surgery are still controversial.[11, 12, 13 , 14].

In this study, we retrospectively analyzed 1023 consecutive patients with esophageal cancer undergoing MIE-McKeown in our hospital from Mar 2013 to Oct 2020. The aim of this paper was to evaluate the technical feasibility, safety and the clinical outcomes of MIE-McKeown in a large cohort of patients from Henan province, the highest incidence area of esophageal cancer in china.

\section{Methods}

\section{Study design and participants}

From Mar 2013 to Oct 2020, overall 1023 patients were enrolled, including 605 males and 408 females, with a mean age of $64.14 \pm 7.12$ years (range, $39-85$ years) and mean tumor length of $3.78 \pm 1.57 \mathrm{~cm}$ (range, $0.5-12 \mathrm{~cm}$ ). For histopathology, the proportion of squamous cell carcinoma was $97.8 \%$ (1000/1023), small cell carcinoma with $1.4 \%$ (15/1023), carcinosarcoma with $0.4 \%$ (4/1023), and adenocarcinoma with $0.4 \%$ (4/1023). Other detailed clinical characteristics were presented in Table 1. 
Table 1

Demographics and clinicopathological parameters $(n=1023)$.

\begin{tabular}{|c|c|c|}
\hline Variables & $N=1023$ & Rate(\%) \\
\hline \multirow[t]{3}{*}{ Demography } & Age $($ mean $\pm S D)$ & $64.14 \pm 7.12$ \\
\hline & Male: \%(n/n) & $59.2(605 / 1023)$ \\
\hline & Female: \%(n/n) & $40.9(418 / 1023)$ \\
\hline \multirow[t]{3}{*}{ ASA-Score } & ASA-1: \%(n/n) & $70.0(716 / 1023)$ \\
\hline & ASA-2: $\%(n / n)$ & $26.9(275 / 1023)$ \\
\hline & ASA-3: \%(n/n) & $3.1(32 / 1023)$ \\
\hline \multirow[t]{5}{*}{ Comorbidity } & Hypertension: \%(n/n) & $20.8(213 / 1023)$ \\
\hline & Diabetes: \%(n/n) & $6.6(68 / 1023)$ \\
\hline & COPD: \%(n/n) & $1.3(13 / 1023)$ \\
\hline & Liver cirrhosis: \%(n/n) & $0.7(7 / 1023)$ \\
\hline & Coronary artery disease: $\%(n / n)$ & $2.5(26 / 1023)$ \\
\hline \multirow[t]{3}{*}{ Location of lesion } & Upper third: \%(n/n) & $23.2(238 / 1023)$ \\
\hline & Middle third: \%(n/n) & $65.7(672 / 1023)$ \\
\hline & Lower third: \%(n/n) & $11.0(113 / 1023)$ \\
\hline \multirow[t]{4}{*}{ Histological type } & Squamous carcinoma: $\%(n / n)$ & $97.8(1000 / 1023)$ \\
\hline & Adenocarcinoma: \%(n/n) & $0.4(4 / 1023)$ \\
\hline & small cell carcinoma: $\%(\mathrm{n} / \mathrm{n})$ & $1.5(15 / 1023)$ \\
\hline & sarcocarcinoma: \%(n/n) & $0.4(4 / 1023)$ \\
\hline \multirow[t]{3}{*}{ Tumor size } & $\leq 3 \mathrm{~cm}: \%(\mathrm{n} / \mathrm{n})$ & $40.1(410 / 1023)$ \\
\hline & $3 \mathrm{~cm} \sim 5 \mathrm{~cm}: \%(\mathrm{n} / \mathrm{n})$ & $35.1(359 / 1023)$ \\
\hline & $\geq 5 \mathrm{~cm}: \%(\mathrm{n} / \mathrm{n})$ & $24.8(254 / 1023)$ \\
\hline Surgery-alone & $\mathrm{n}(\%)$ & $91.1(932 / 1023)$ \\
\hline \multirow[t]{4}{*}{ Pathological T stage (\%) } & Tis 1: \%(n/n) & $23.6(220 / 932)$ \\
\hline & T2: \%(n/n) & $22.5(210 / 932)$ \\
\hline & T3: \%(n/n) & $44.9(418 / 932)$ \\
\hline & $\mathrm{T} 4: \%(\mathrm{n} / \mathrm{n})$ & $9.0(84 / 932)$ \\
\hline Pathological N stage (\%) & NO: $\%(n / n)$ & $61.3(571 / 932)$ \\
\hline
\end{tabular}




\begin{tabular}{|c|c|c|}
\hline \multirow[t]{4}{*}{ Variables } & $N=1023$ & Rate(\%) \\
\hline & $\mathrm{N} 1: \%(\mathrm{n} / \mathrm{n})$ & $24.9(232 / 932)$ \\
\hline & $\mathrm{N} 2: \%(\mathrm{n} / \mathrm{n})$ & $10.8(101 / 932)$ \\
\hline & N3: \%(n/n) & $3.0(28 / 932)$ \\
\hline \multirow[t]{6}{*}{ Pathological TNM stage (\%) } & IO-IB: \%(n/n) & $21.4(199 / 932)$ \\
\hline & $\| A: \%(n / n)$ & $16.5(154 / 932)$ \\
\hline & IIB: \%(n/n) & $21.6(201 / 932)$ \\
\hline & IIIA: \%(n/n) & $6.3(59 / 932)$ \\
\hline & IIIB: \%(n/n) & $27.7(258 / 932)$ \\
\hline & IVA: \%(n/n) & $6.5(61 / 932)$ \\
\hline \multirow[t]{3}{*}{ Neoadjuvant chemotherapy with surgery } & $\%(n / n)$ & $8.9(91 / 1023)$ \\
\hline & CllIB: \%(n/n) & $70.3(64 / 91)$ \\
\hline & clVA: $\%(n / n)$ & $29.7(27 / 91)$ \\
\hline Thoracoscopy combined with laparotomy & $\%(n / n)$ & $78.6(804 / 1023)$ \\
\hline Thoracoscopy combined with laparoscopy & $\%(n / n)$ & $21.4(219 / 1023)$ \\
\hline
\end{tabular}

All patients were diagnosed as esophageal cancer by upper gastrointestinal endoscopy and biopsy. Simultaneously, comprehensive pre-operative evaluations were carried out. Patients with pre-operative TNM stage (AJCC staging manual, 8th edition) >llla were recommened for neoadjuvant therapy. Meanwhile, patients with staging pIII-pIVA received adjuvant therapy.

The inclusion criteria were: (i) definitive diagnosis of esophageal cancer. (ii) preoperative clinical staging (AJCC.2018) T:1-4A, N:0-2, M:0; (iii) accepted MIE-McKeown. (iv) ASA score (American Society of Anesthesiologists) 1-3. The exclusion criteria were: (i) extensive thoracic or abdominal adhesion; (ii) patients with unresectable or distant metastasis; (iii) patients can not tolerate MIE for obvious dysfunction of vital organs; (iv) impaired coagulation; (v). death unrelated to the carcinoma.

\section{Surgical Approach}

\section{Thoracoscopic mobilization of thoracic segment of esophagus and tumor}

All patients were intubated with double lumen tubes for one lung ventilation with the help of an open pneumothorax instead of a $\mathrm{CO}_{2}$ artificial pneumothorax, and all patients were set in the lateral decubitus position during the thoracic stage. Thoracoscopy was performed with four thoracic ports: the camera port $(1.0 \mathrm{~cm})$ was located at the 7th intercostal space on the anterior axillary line, two major operation ports were located at the 5 th $(1.0 \mathrm{~cm})$ and 8 th $(0.5 \mathrm{~cm})$ intercostal space on the scapular line, respectively. 
Another operation port (a small open incision, $2.5 \mathrm{~cm}$ ) for the assistant at the 4th intercostal space on the anterior axillary line. The surgeon stood facing the patient's back and the opposite were the thoracoscopic technician and the first assistant. Thoracoscopic mobilization of thoracic segment of esophagus was carried out from esophageal hiatus to supraclavicular artery level in a bottom-up approach. Thoracic lymph nodes were systematically dissected and the thoracic duct was selectively ligated between the azygos vein and the descending aorta at the level of the 10th thoracic vertebra. Finally, a single thoracic cannula was inserted to complete the thoracoscopic surgery.

\section{Laparoscopic mobilization of the stomach}

After completing the thoracoscopic operation, the patients were given double lung ventilation and repositioned in a supine position with the upper body elevated by $30^{\circ}$. Camera port $(12 \mathrm{~mm})$ was placed below the umbilicus, and a $\mathrm{CO}_{2}$ artificial pneumoperitoneum of $11-13 \mathrm{mmHg}$ was established. Other four trocars were inserted in the form of a "V"-shaped distribution, and the positions of surgeon and assistants standed were variable according to the anatomical characteristics and the surgeon's habits. The stomach was routinely mobilized and the abdominal lymph nodes were systematically dissected. Ultimately, a gastric conduit about $3.5 \mathrm{~cm}$ in diameter was created using a linear stapler outside the abdominal cavity through a 5-8 $\mathrm{cm}$ incision.

\section{Anastomosis}

An approximate 4-6 cm oblique incision was made over the anterior border of the left sternocleidomastoid muscle. The neck esophagus was mobilized and cervical lymph node were dissected when maximum short axis diameter of lymph nodes more than $0.8 \mathrm{~cm}$. Ultimately, the gastric conduit was pulled up to the left neck through the posterior mediastinum to enable esophagogastric stapled anastomosis.

\section{Anesthesia}

All cases underwent intravenous anesthesia and inhalation anesthesia through a double-lumen endotracheal tube. Two-lung ventilation was administered during the abdominal stage, while single leftlung ventilation was performed during the thoracic stage and anesthesia stage.

\section{Study endpoints}

The primary endpoint was the 3,5-year overall survival (OS) time. Secondary endpoints were the shortterm outcomes, including operative time, total blood loss, R0 resection rate, total and positive numbers of dissected lymph nodes, 30-day postoperative mortality, length of hospital stay and ICU stay, postoperative recovery, and the incidence of treatment-related complications.

\section{Postoperative care}


The patients were given enteral nutrition at postoperative 1-day through a nasal feeding tube, and started eating at 5-7 days after operation if there weren't any signs of leakage and functional gastric conduit evacuating disturbance examined by a barium swallow on all patients.

\section{Flollow-up}

All patients received postoperative follow-up every 3-month during the first year and every 6-month thereafter at the outpatient department. Simultaneously, telephone follow-up every 3-month conducted by LinkDoc company. Overall survival (OS) was the interval from the day of surgery to death or the last follow-up date (Oct. 2019).

\section{Statistical Analysis}

Descriptive statistics were provided, continuous variables were presented as mean $\pm S D$, categorical variables as distribution ratio. Survival was analyzed by Kaplan-Meier method for patients with squamous cell carcinoma. All statistical analyses were performed with a dedicated analysis tool (SPSS 25.0 statistical software package; SPSS, Chicago, II, USA).

\section{Results}

\section{Intraoperative Complications and Outcomes}

A total of 1023 patients underwent MIE-Mckeown surgery successfully and without intraoperative death occoured. The surgical procedures and results were listed in Table 2. The most common severe intraoperative complication were hemorrhage $(3.0 \%, 31 / 1023)$, and the next was tracheal injury $(1.7 \%$, 17/1023). 8 patients received emergency conversion to open surgery due to intraoperative bleeding (5 thoracotomy, 3 laparoscopy). Another 17 patients suffered from emergency conversion because of failure of lung septation $(n=2)$ and bulky tumor $(n=15)$. 
Table 2

Operative and post-operative parameters.

\begin{tabular}{|c|c|c|}
\hline Variables & $N=1023$ & \\
\hline Operation time (min) & average $($ mean $\pm S D)$ & $215.77 \pm 50.33$ \\
\hline Total blood loss (mL) & average $($ mean $\pm S D)$ & $224.13 \pm 156.11$ \\
\hline 72h-postoperative drain volume (ml) & average $($ mean $\pm S D)$ & $698.13 \pm 428.34$ \\
\hline Chest drain removal (day) & average $($ mean $\pm S D)$ & $2.02 \pm 1.75$ \\
\hline Post-operative hospital stay (days) & average $($ mean $\pm S D)$ & $16.69 \pm 10.74$ \\
\hline ICU stay (days) & average (mean $\pm S D)$ & $1.30 \pm 2.62$ \\
\hline No. of lymph nodes harvested & average (mean $\pm S D)$ & $19.09 \pm 8.12$ \\
\hline Mediastinal & average (mean $\pm S D)$ & $12.66 \pm 5.97$ \\
\hline Left recurrent laryngeal nerve & average (mean $\pm S D)$ & $2.35 \pm 1.74$ \\
\hline Right recurrent laryngeal nerve & average (mean $\pm S D)$ & $2.27 \pm 1.98$ \\
\hline Abdominal: average & average (mean $\pm S D)$ & $6.43 \pm 4.79$ \\
\hline No. stations of lymph node dissected & average (mean $\pm S D)$ & $6.63 \pm 1.46$ \\
\hline R0 resection & $\%(n / n)$ & $96.0(982 / 1023)$ \\
\hline \multicolumn{3}{|l|}{ Intraoperative complication } \\
\hline Bleeding & $\%(n / n)$ & $3.0(31 / 1023)$ \\
\hline Tracheal injury & $\%(n / n)$ & 1.7(17/1023) \\
\hline Conversion thoracoscopy & $\%(n / n)$ & $2.2(22 / 1023)$ \\
\hline \multicolumn{3}{|l|}{ Reason for conversion } \\
\hline Failure of lung septation. & constituent ratio $\%(n / n)$ & $9.1(2 / 22)$ \\
\hline Bleeding & constituent ratio $\%(n / n)$ & $22.7(5 / 22)$ \\
\hline Bulky tumor(T4) & constituent ratio $\%(n / n)$ & $68.2(15 / 22)$ \\
\hline Pleural or peritoneal adhesions & constituent ratio $\%(n / n)$ & 0 \\
\hline Conversion laparoscopy & $\%(n / n)$ & $0.3(3 / 1023)$ \\
\hline \multicolumn{3}{|l|}{ Reason for conversion } \\
\hline Bleeding & constituent ratio $\%(n / n)$ & $100(3 / 3)$ \\
\hline
\end{tabular}

The average overall operation time was $215.77 \pm 50.33 \mathrm{~min}$ (range, 50-720 $\mathrm{min}$ ) and the average intraoperative blood loss was $224.13 \pm 156.11 \mathrm{ml}$ (range, 50-2300 ml). Postoperative thoracic tube 
drainage was performed for 1-22 days, with an average of $2.02 \pm 1.75$ days. The 72 -hour postoperative chest drainage volume was $698.13 \pm 428.34 \mathrm{ml}$ (range, $30-3915 \mathrm{ml}$ ). The median ICU stay was 1 days (range, $0-28$ days) and the average post-operative hospital stay was $16.69 \pm 10.74$ days (range, 7-86 days).

The median mean number of lymph nodes retrieved was $19.09 \pm 8.12$ (range, 6-58), and the harvested lymph node station was $6.63 \pm 1.46$. The average number of harvested mediastinal lymph nodes was $12.66 \pm 5.97$ (range, $2-50$ ), and the harvested abdominal nodes was $6.43 \pm 4.79$ (range, $0-33$ ). The radical resection (R0) rate was $96.0 \%(982 / 1023)$.

\section{Postoperative Complications}

Detailed post-operative complications were shown in Table 3. Major surgical complications occurred in 370 patients $(36.2 \%, 370 / 1023)$. Unplanned secondary operation were performed in 10 cases. Vocal cord palsy developed in 90 patients (8.8\%) in whom 68 cases recovered within 3 to 6 weeks, 22 patients' vocal cord palsy was permanent. Anastomotic leakage was detected in 79 patients $(7.7 \%)$ in whom 2 cases required a follow-up operation, 1 cases eventually died of tracheal fistula, and the remaining cases were managed conservatively through nutritional support. 24 cases $(2.3 \%)$ diagnosed with chylothorax in whom 4 cases received secondary operation (thoracic duct ligation), and the remaining cases were managed conservatively. 53(5.2\%) cases were diagnosed as anastomotic stenosis and cured by gastroscopic dilatation or esophageal stenting. The most common non-surgical complications was pulmonary complications $(n=137)$, in whom 94 cases with respiratory pneumonia, 18 with ARDS, 12 with pneumothorax, 10 with respiratory failure, and 3 with pulmonary embolism. $45(4.4 \%)$ cases developed atrial fibrillation, and $14(1.4 \%)$ cases developed delayed gastric emptying, of which 2 cases were treated with conservative treatments such as pyloric stents. 
Table 3

Postoperative complications.

\begin{tabular}{|c|c|c|c|}
\hline Variables & $\mathbf{N}$ & $\%(n / n)$ & constituent ratio $\%(n / n)$ \\
\hline Total post-operative complications & 370 & $36.2(370 / 1023)$ & - \\
\hline \multicolumn{4}{|l|}{ Major surgical complications } \\
\hline Unplanned second operation & 10 & $1.0(10 / 1023)$ & \\
\hline Post-operative hemorrhage & 4 & $0.4(4 / 1023)$ & \\
\hline Chyle leakage & 4 & $0.4(4 / 1023)$ & \\
\hline Anastomotic leak & 2 & $0.2(2 / 1023)$ & \\
\hline Anastomotic leakage & 79 & 7.7(79/1023) & \\
\hline Type I(conservative) & 18 & & $22.8(18 / 79)$ \\
\hline Type II(nonsurgical intervation) & 59 & & $74.7(59 / 79)$ \\
\hline Type III(second operation) & 2 & & $2.5(2 / 79)$ \\
\hline Anastomotic stenosis & 53 & $5.2(53 / 1023)$ & \\
\hline Vocal cord palsy & 90 & $8.8(90 / 1023)$ & \\
\hline Temporary (recovered in 2 weeks) & 68 & & $75.6(68 / 90)$ \\
\hline Permanent & 22 & & $24.4(22 / 90)$ \\
\hline Chylothorax & 24 & $2.3(24 / 1023)$ & \\
\hline Type I(Low fat dietary) & 5 & & $20.8(5 / 24)$ \\
\hline Type II(total parenteralnutrition) & 15 & & $62.5(15 / 24)$ \\
\hline Type III(surgical intervation) & 4 & & $16.7(4 / 24)$ \\
\hline \multicolumn{4}{|l|}{ Major non-surgical morbidity } \\
\hline Pulmonary complication & 137 & 13.4(137/1023) & \\
\hline Respiratory pneumonia & 94 & & $68.6(94 / 137)$ \\
\hline ARDS & 18 & & 13.1(18/137) \\
\hline Pneumothorax & 12 & & $8.8(12 / 137)$ \\
\hline Respiratory failure & 10 & & 7.3(10/137) \\
\hline Pulmonary embolism & 3 & & $2.2(3 / 137)$ \\
\hline Atrial fibrillation & 45 & $4.4(45 / 1023)$ & \\
\hline Delayed gastric emptying & 14 & $1.4(14 / 1023)$ & \\
\hline
\end{tabular}




\begin{tabular}{|llll|}
\hline Variables & $\mathbf{N}$ & $\%(\mathrm{n} / \mathrm{n})$ & constituent ratio $\%(\mathrm{n} / \mathrm{n})$ \\
\hline 30-Day mortality & 3 & $0.3(3 / 1023)$ & \\
\hline Anastomotic leak & 1 & $0.1(1 / 1023)$ & $33.3(1 / 3)$ \\
\hline DIC & 1 & $0.1(1 / 1023)$ & $33.3(1 / 3)$ \\
\hline Aspiration pneumonia & 1 & $0.1(1 / 1023)$ & $33.3(1 / 3)$ \\
\hline
\end{tabular}

The 30 -day mortality rate was $0.3 \%(3 / 1023)$ and the causes of death were pulmonary infection $(33.3 \%$, $1 / 3)$, anastomotic leakage $(33.3 \% 1 / 3)$ and DIC (33.3\% 1/3) respectively.

\section{Follow-up And Survival Analysis}

For 1000 cases with squamous cell carcinoma, successful follow-up was completed on 978 patients (97.8\%), up to the last follow up in Oct. 2020. The median follow-up time was 37.5 months (range 1-92 month). The estimated 3-year overall survival was $65.1 \%$ [95\% confidence interval (Cl): $58.3-81.7 \%]$, the estimated 5-year overall survival was $52.7 \%$ (95\% Cl: $57.9-76.2 \%)$. In the subsets of stage I, II, III, IV without neo-adjuvant therapy, the estimated 3-year and 5-year overall survival were $93.6 \%, 89.1 \%$ in stage I, $73.5 \%$ and $59.4 \%$ in stage II, $50.3 \%$ and $32.9 \%$ in stage III, $17.0 \%$ and $7.1 \%$ in stage IV, respectively. For patients undergoing neoadjuvant therapy, the estimated 3-year and 5-year overall survival was $61.7 \%$ and $53.1 \%$ for stage clll, $30.4 \%$ and $20.3 \%$ for stage cIV. Neo-adjuvant therapy offered survival advantages in advanced stage patients. Kaplan-Meier survival curve among each TNM stage was plotted and demonstrated in Fig. 1.

\section{Discussion}

Esophagectomy and reconstruction remain the standard procedure in the curative intent treatment for patients with resectable esophageal cancer. In attempts to reduce the complications' morbidity and mortality of open esophagectomy, MIE has been widely used worldwide in recent years. Some prospective and meta-analysis studies have showed the potential short-term benefits of MIE, including less blood loss, lower incidence of respiratory complications, shorter hospital or ICU stays, and faster surgical recovery $[13,15,16,17]$. Currently, McKeown with cervical esophagogastric anastomosis and Ivor Lewis with thoracic esophagogastric anastomosis surgery were the most common surgical procedures in esophagectomy. Several studies have showed that MIE-McKeown procedure was associated with higher incidence of recurrent laryngeal nerve injury, pneumonia and anastomotic leakage than Ivor-Lewis[18, 19, 20 , 21]. However, MIE-McKeown also has some potential benefits, such as more proximal resection margin and more lymph nodes dissected, which seems to improve long-term survival[22, 23]. Thus, the MIE-McKeown procedure combined three-field lympadenectomy is recommended as a routine approach in China and Japan[7, 23, 24]. At present, approximately 700 patients with esophageal cancer underwent MIE-McKeown at our institution per year. This study included 1023 consecutive cases undergoing MIEMcKeown procedure, representing a single center large sample study, suggesting that the MIE-McKeown 
is feasible and can be safely performed with a 30-day mortality rate of $0.3 \%$, a mean ICU stay of 1.3 days, and a median postoperative hospital stay of 12 days. In term of main postoperative complications, anastomotic leakage rate was $7.7 \%$, pulmonary complication rate $13.4 \%$, chyle leakge rate $2.3 \%$ and recurrent laryngeal nerve $(\mathrm{RLN})$ injury rate $8.8 \%$. These short-term outcomes of the procedure at our institution are equivalent to or superior to most published literatures[21, 25, 26, 27, 28].

According to our experience, prevention is key to the treatment of complications. Bleeding is known to be a common cause of unplanned surgical exploration after esophagectomy, accounting for $40 \%(4 / 10)$ of all secondary operation in our study. Hemorrhages and incision bleeding can be effectively prevented by careful examinations. In addition, chyle leakage is another common complication in open esophagectomy or MIE, causing unplanned surgical exploration. The previously reported incidence varies from $0.8-5.9 \%[25,29]$ and $2.3 \%$ in our study. At present, the effectiveness of prophylactic thoracic duct ligation on preventing chylothorax still remains controversial[29,30]. Moreover, the potential impact of thoracic duct ligation on long-term survival has not been determined. According to our experience, routine thoracic duct ligation was recommended for middle or upper esophageal cancer with T3-T4, and should be performed when thoracic duct was damaged definitely or suspiciously. In addition, several studies found that preoperative oral administration of olive oil can effectively pevent chylothorax[31, 32].

Anastomotic leakage after esophagectomy is one of the most severe complications. Some studies have shown that the incidence of neck anastomosis in Mckeown surgery is higher than that in Ivor Lewis surgery with intrathoracic anastomosis $[18,19,20]$. The reported incidence varies from $5-23.3 \%[15,18$, $21,25,27,33]$ and $7.7 \%$ in our study. Tracheal fistula, one of the most fatal complications, accounting for $33.3 \%(1 / 3)$ of all deaths within 30 days after surgery in our study, was often caused by gastric acid or other pollutant secretions from anastomotic leakage. A large sample review, including 25 articles, gave evidence that anemia, increased amount of blood loss, low pH and high $\mathrm{PCO}_{2}$ values, prolonged surgery time and poor technique independently increased the risk of anastomotic leakage[34]. Therefore, some measures, such as gsatroprotection of blood supply, improvement of anastomotic technique, perioperative nutrition support and relieving the tension of anastomosis, can effectively reduce the incidence of the complications $[34,35,36]$.

Besides anastomotic leak, pneumonia was the most observed complication following MIE. Previous studies showed that its incidence ranged from $9.0-31.9 \%$, and was $13.4 \%$ in our study. Most of these cases were cured by conservative treatment and with 1 case died of aspiration pneumonia,which caused by recurrent laryngeal nerve (RLN) injury. Notably, RLN injury can be caused by contusions, excessive stretching and thermal damage occurring when dissecting the lymph nodes surrounding the left and right $\mathrm{RLN}[38]$. So, it is essential to protect RLN from burning or shearing during manipulation.

Considering the high incidence of lymphatic metastasis surrounding RLN[39], we must dissect the lymph nodes in these fields. However, the meticulous dissection in a narrow space is still challenging and frequently leads to RLN palsy[38]. As operative experience increased, the rate of hoarseness in our center gradually decreased by avoiding stretching, compression and thermal injury on the RLN. Regarding the

Page 12/19 
left RLN prevention, it is critical to clearly expose the RLN bluntly before lymph node dissection. In order to obtain an optimal visualization, we used some methods, such as the single lumen intubation, turn lateral decubitus position to semi prone position, assistant' pull force from opposite side, which were conducive to dissect the left RLN easily[40].

The potential benefits of MIE-McKeown are a more proximal resection margin and improved lymph node dissection, which can provide more accurate pathological staging and improve patient survival, especially for patients with middle or upper thoracic esophageal cancer[7, 22, 23]. However, several prospective and observed studies showed that MIE-McKeown with three-filed lymphadenectomy has not prolonged the survival time than open procedure or MIE Ivor-Lewis, and even though yielded more lymph nodes[41, 42, 43,44 ]. In our study, $55.9 \%$ of cases were in stage of T3-T4, 38.7\% with nodal positive (N1-3), and $34.2 \%$ with locally advanced esophageal carcinoma (IIIB口IVA stage). Our results showed that MIE-McKeown provided a high percentage of R0 radical resections (96.0\%), adequate lymphadenectomy (the mean number of lymph nodes dissected 19.09, the mean number of lymph node stations 6.63 ), and obtained a $65.1 \%$ of 3 -year OS and $52.7 \%$ of 5 -year OS in squamous cell carcinoma, which was equivalent or superior to that reported for open esophagectomy or MIE Lvor-Lewis[12, 14, 23, 27, 28, 34, 36]. These results indicated that MIE McKeown method satisfied the oncological requirements and did not impact long-term survival rates. In addition, neoadjuvant chemotherapy seemd to offer 5-year survival advantage in advanced stage patients(for stage III: $53.1 \%$ vs. $32.9 \%$, and for stage IV: $20.3 \%$ vs. $7.1 \%$ ).

However, this clinical research has a number of limitations. First, this trial was a single central retrospective study lacking of control group to compare the surgical outcomes. Second, data on quality of life, functional results and cost-effectiveness have not been studied. Third, in this study, neoadjuvant therapy followed by esophagectomy for locally advanced ESCC seemed to improve long-term survival compared with surgery alone, but we did not conduct a rigorous design to confirm the survival advantage. Lastly, although the sample size is large in this study, multicenter randomized controlled trials (RCTs) should be conducted in the future work to verify the equivalency or advantages of MIE-Mckeown compared with open esophagectomy or MIE-Lvor Lewis.

\section{Conclusion}

This single-center experience demonstrate that MIE-McKeown with standard three-field lymphadenectomy is a safe and feasible procedure of resectable esophageal cancer. It offers satisfactory surgical outcomes and long-term clinical outcomes such as a high radical resection rate, adequate lymphadenectomy, and long overall survival time. Further researches with prospective multicenter randomized controlled trials are needed to clinically validate these findings.

\section{Abbreviations}


Overall survival; MIE:minimally invasive esophagectomy;ICU:Intensive Care Unit; Cl:confidence interval; RLN:recurrent laryngeal nerve; RCTs:randomized controlled trials

\section{Declarations}

\section{Acknowledgements}

Not applicabe.

\section{Authors' contributions}

Informed consent statement: Verbal informed consent was obtained from the patient(s) for their anonymized information to be published in this article.

Analyzed the data: Xiao-Dong Zheng.

Wrote the paper: Xiao-Dong Zheng.

Contributed reagents/ materials: Ke-Feng Shi.

Contributed analysis tools: Shi-Cong Li.

Contributed article revision: Chao Lu

\section{Funding}

None.

\section{Availability of data and materials}

The data that support the findings of this study are available from the corresponding author upon reasonable request.

\section{Ethical approval and consent to participate}

The present study was a part of Phase III clinical trial (ClinicalTrials.gov Identifier: NCT02448979) sponsored by the Institutional Review Board of Cancer Hospital, Chinese Academy of Medical Science and received ethics board approval (NCC2014 ZC-01).

\section{Consent for publication}

Not applicable.

\section{Competing interests}

The authors declare that they have no competing interests. 


\section{References}

1. Bray F, Ferlay J, Soerjomataram I, et al. Global cancer statistics 2018: GLOBOCAN estimates of incidence and mortality worldwide for 36 cancers in 185 countries. CA Cancer J Clin. 2018;68(6):394-424. doi:10.3322/caac.21492.

2. Gupta B, Kumar N. Worldwide incidence, mortality and time trends for cancer of the oesophagus. Eur J Cancer Prev. 2017;26(2):107-18. doi: 10.1097/CEJ.0000000000000249.

3. Zeng H, Chen W, Zheng R, et al. Changing cancer survival in China during 2003-15: a pooled analysis of 17 population-based cancer registries. Lancet Global health. 2018;6(5):e555-67. doi:10.1016/S2214-109X(18)30127-X.

4. Jiang R, Liu Y, Ward KC, et al. Excess Cost and Predictive Factors of Esophagectomy Complications in the SEER-Medicare Database. Ann Thorac Surg. 2018;106(5):1484-91. doi:

10.1016/j.athoracsur.2018.05.062.

5. Low DE, Kuppusamy MK, Alderson D,et al. Benchmarking Complications Associated with Esophagectomy. Ann Surg. 2019;269(2):291-8. doi: 10.1097/SLA.0000000000002611.

6. Chen J, Wu S, Zheng X, et al. Cervical lymph node metastasis classified as regional nodal staging in thoracic esophageal squamous cell carcinoma after radical esophagectomy and three-field lymph node dissection. BMC Surg. 2014;14:110. Doi. 10.1186/1471-2482-14-110.

7. Matsuda S, Takeuchi H, Kawakubo H, et al. Three-field lymph node dissection in esophageal cancer surgery. J Thorac Dis. 2017;9(8):731-40. doi:10.21037/jtd.2017.03.171.

8. Oshikiri T, Takiguchi G, Miura S, et al. Current status of minimally invasive esophagectomy for esophageal cancer: Is it truly less invasive? Ann Gastroenterol Surg. 2018;3(2):138-45. doi: 10.1002/ags3.12224.

9. Shanmugasundaram R, Hopkins R, Neeman T, et al. Minimally invasive McKeown's vs open oesophagectomy for cancer: A meta-analysis. Eur J Surg Oncol. 2019;45(6):941-9. doi:10.1016/j.ejso.2018.11.017.

10. Takeuchi H, Miyata H, Ozawa S, et al. Comparison of Short-Term Outcomes Between Open and Minimally Invasive Esophagectomy for Esophageal Cancer Using a Nationwide Database in Japan. Ann Surg Oncol. 2017;24(7):1821-7. doi:10.1245/s10434-017-5808-4.

11. Gottlieb-Vedi E, Kauppila JH, Malietzis G, et al. Long-term Survival in Esophageal Cancer After Minimally Invasive Compared to Open Esophagectomy: A Systematic Review and Meta-analysis. Ann Surg. 2019;270(6):1005-17. doi:10.1097/SLA.0000000000003252.

12. Straatman J, van der Wielen N, Cuesta MA, et al. Minimally Invasive Versus Open Esophageal Resection: Three-year Follow-up of the Previously Reported Randomized Controlled Trial: the TIME Trial. Ann Surg. 2017;266(2):232-6. doi:10.1097/SLA.0000000000002171.

13. Giugliano DN, Berger AC, Rosato EL, et al. Total minimally invasive esophagectomy for esophageal cancer: approaches and outcomes. Langenbecks Arch Surg. 2016;401(6):747-56. doi:10.1007/s00423-016-1469-1. 
14. Hsu PK, Huang CS, Wu YC, Chou TY, Hsu WH. Open versus thoracoscopic esophagectomy in patients with esophageal squamous cell carcinoma. World J Surg. 2014;38(2):402-9. doi:10.1007/s00268013-2265-5.

15. Yoshida N, Yamamoto H, Baba H, et al. Can Minimally Invasive Esophagectomy Replace Open Esophagectomy for Esophageal Cancer? Latest Analysis of 24,233 Esophagectomies From the Japanese National Clinical Database [published online ahead of print, 2019 Jan 31]. Ann Surg. 2019. doi:10.1097/SLA.0000000000003222.

16. Biere SS, van Berge Henegouwen MI, Maas KW, et al. Minimally invasive versus open oesophagectomy for patients with oesophageal cancer: a multicentre, open-label, randomised controlled trial. Lancet. 2012;379(9829):1887-92. doi:10.1016/S0140-6736(12)60516-9.

17. van der Sluis PC, van der Horst S, May AM, et al. Robot-assisted Minimally Invasive Thoracolaparoscopic Esophagectomy Versus Open Transthoracic Esophagectomy for Resectable Esophageal Cancer: A Randomized Controlled Trial. Ann Surg. 2019;269(4):621-30. doi:10.1097/SLA.0000000000003031.

18. van Workum F, Slaman AE, van Berge Henegouwen MI, et al. Propensity Score-Matched Analysis Comparing Minimally Invasive Ivor Lewis Versus Minimally Invasive Mckeown Esophagectomy. Ann Surg. 2020;271(1):128-33. doi:10.1097/SLA.0000000000002982.

19. Deng J, Su Q, Ren Z, et al. Comparison of short-term outcomes between minimally invasive McKeown and Ivor Lewis esophagectomy for esophageal or junctional cancer: a systematic review and meta-analysis. Onco Targets Ther. 2018;11:6057-69. doi:10.2147/OTT.S169488. Published 2018 Sep 20.

20. Biere SS, Maas KW, Cuesta MA, et al. Cervical or thoracic anastomosis after esophagectomy for cancer: a systematic review and meta-analysis. Dig Surg. 2011;28(1):29-35.

doi:10.1159/000322014.

21. Luketich JD, Pennathur $A$, Awais 0 , et al. Outcomes after minimally invasive esophagectomy: review of over 1000 patients. Ann Surg. 2012;256(1):95-103. doi:10.1097/SLA.0b013e3182590603.

22. Ma GW, Situ DR, Ma QL, et al. Three-field vs two-field lymph node dissection for esophageal cancer: a meta-analysis. World J Gastroenterol. 2014;20(47):18022-30. doi:10.3748/wjg.v20.i47.18022.

23. Ando N, Ozawa S, Kitagawa Y, et al. Improvement in the results of surgical treatment of advanced squamous esophageal carcinoma during 15 consecutive years. Ann Surg. 2000;232(2):225-32. doi:10.1097/00000658-200008000-00013.

24. Expert committee of esophageal surgery of Chinese Medical Association. Fang WT, Zhang X. Expert consensus on minimally invasive esophagectomy (MIE). Chin J Thorac Cardiovasc Surg. 2013,29(7):385-7. doi:10.3760/cma.j.issn.1001-4497.2013.07.001.

25. Sakamoto T, Fujiogi M, Matsui H, et al. Comparing Perioperative Mortality and Morbidity of Minimally Invasive Esophagectomy Versus Open Esophagectomy for Esophageal Cancer: A Nationwide Retrospective Analysis [published online ahead of print, 2019 Jul 25]. Ann Surg. 2019. doi:10.1097/SLA.0000000000003500. 
26. Thirunavukarasu P, Gabriel E, Attwood K. et.al. Nationwide analysis of short-term surgical outcomes of minimally invasive esophagectomy for malignancy. Int J Surg. 2016;25:69-75. doi:10.1016/j.ijsu.2015.11.023.

27. Luketich JD, Pennathur A, Franchetti Y, et al. Minimally invasive esophagectomy: results of a prospective phase II multicenter trial-the eastern cooperative oncology group (E2202) study. Ann Surg. 2015;261(4):702-7. doi:10.1097/SLA.0000000000000993.

28. Lerut T, Nafteux P, Moons J, et al. Three-field lymphadenectomy for carcinoma of the esophagus and gastroesophageal junction in $174 \mathrm{R} 0$ resections: impact on staging, disease-free survival, and outcome: a plea for adaptation of TNM classification in upper-half esophageal carcinoma. Ann Surg. 2004;240(6):962-74. doi:10.1097/01.sla.0000145925.70409.d7.

29. Lei Y, Feng Y, Zeng B, et al. Effect of Prophylactic Thoracic Duct Ligation in Reducing the Incidence of Postoperative Chylothorax during Esophagectomy: A Systematic Review and Meta-analysis. Thorac Cardiovasc Surg. 2018;66(5):370-5. doi:10.1055/s-0037-1602259.

30. Bao T, Wang YJ, Li KK, et al. Guo W. Short- and long-term outcomes of prophylactic thoracic duct ligation during thoracoscopic-laparoscopic McKeown esophagectomy for cancer: a propensity score matching analysis [published online ahead of print, 2019 Dec 11]. Surg Endosc. 2019. doi:10.1007/s00464-019-07297-6.

31. Du ZS, Li XY, Luo HS, et al. Preoperative Administration of Olive Oil Reduces Chylothorax After Minimally Invasive Esophagectomy. Ann Thorac Surg. 2019;107(5):1540-3. doi:10.1016/j.athoracsur.2018.10.053.

32. Lin Y, Li Z, Li G, et al. Selective En Masse Ligation of the Thoracic Duct to Prevent Chyle Leak After Esophagectomy. Ann Thorac Surg. 2017;103(6):1802-7. doi:10.1016/j.athoracsur.2017.01.025.

33. Bootsma BT, Huisman DE, Plat VD, et al. Towards optimal intraoperative conditions in esophageal surgery: A review of literature for the prevention of esophageal anastomotic leakage. Int J Surg. 2018;54(Pt A):113-23. doi:10.1016/j.jjsu.2018.04.045.

34. Fransen LFC, Berkelmans GHK, Asti E, et al. The Effect of Postoperative Complications After Minimally Invasive Esophagectomy on Long-term Survival: An International Multicenter Cohort Study [published online ahead of print, 2020 Jan 14]. Ann Surg. 2020.

doi:10.1097/SLA.0000000000003772.

35. Ishige F, Nabeya Y, Hoshino I, et al. Quantitative Assessment of the Blood Perfusion of the Gastric Conduit by Indocyanine Green Imaging. J Surg Res. 2019;234:303-10. doi:10.1016/j.jss.2018.08.056.

36. Shimakawa T, Naritaka Y, Asaka S, et al. Innovations for Cervical Esophagogastrostomy in Thoracic Esophageal Cancer Operations. Anticancer Res. 2018;38(4):2323-7. doi:10.21873/anticanres.12477.

37. Mariette C, Markar SR, Dabakuyo-Yonli TS, et al. Hybrid Minimally Invasive Esophagectomy for Esophageal Cancer. N Engl J Med. 2019;380(2):152-62. doi:10.1056/NEJMoa1805101.

38. Koyanagi K, Igaki H, Iwabu J, et al. Recurrent Laryngeal Nerve Paralysis after Esophagectomy: Respiratory Complications and Role of Nerve Reconstruction. Tohoku J Exp Med. 2015;237(1):1-8. 
doi:10.1620/tjem.237.1.

39. Tan Z, Ma G, Zhao J, et al. Impact of thoracic recurrent laryngeal node dissection: 508 patients with tri-incisional esophagectomy. J Gastrointest Surg. 2014;18(1):187-93. doi:10.1007/s11605-0132411-2.

40. Cuesta MA. Review of different approaches of the left recurrent laryngeal nerve area for lymphadenectomy during minimally invasive esophagectomy. J Thorac Dis. 2019;11(5):766-70. doi:10.21037/jtd.2018.12.52.

41. Koterazawa Y, Oshikiri T, Takiguchi G, et al. Prophylactic Cervical Lymph Node Dissection in Thoracoscopic Esophagectomy for Esophageal Cancer Increases Postoperative Complications and Does Not Improve Survival. Ann Surg Oncol. 2019;26(9):2899-904. doi:10.1245/s10434-019-074991.

42. Shao L, Ye T, Ma L, et al. Three-field versus two-field lymph node dissection for thoracic esophageal squamous cell carcinoma: a propensity score-matched comparison. J Thorac Dis. 2018;10(5):292432. doi:10.21037/jtd.2018.05.69.

43. Wong J, Weber J, Almhanna K, et al. Extent of lymphadenectomy does not predict survival in patients treated with primary esophagectomy. J Gastrointest Surg. 2013;17(9):1562-9. doi:10.1007/s11605013-2259-5.

44. Nishihira T, Hirayama K, Mori S. A prospective randomized trial of extended cervical and superior mediastinal lymphadenectomy for carcinoma of the thoracic esophagus. Am J Surg. 1998;175:4751. doi:10.1016/S0002-9610(97)00227-4.

\section{Figures}




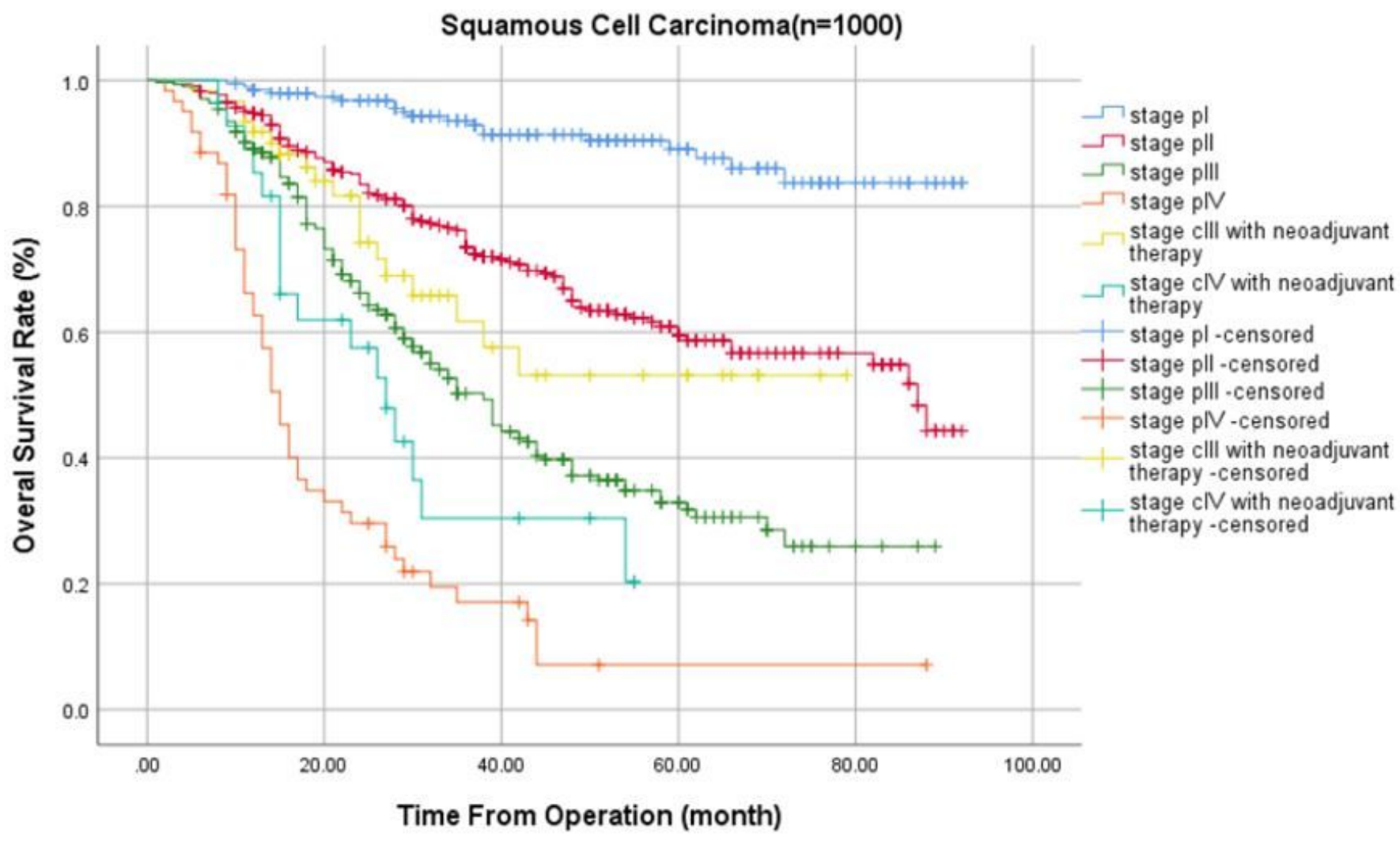

Figure 1

Kaplan-Meier survival curve of patients presenting with esophageal cell carcinoma who received the minimally invasive McKeown esophagectomy, stratified by stage. 